\title{
Conservative Treatment of Idiopathic Spontaneus Pneumoperitoneum
}

\author{
Marina Gabrielle Epstein ${ }^{1 *}$, Vladimir Schraibman ${ }^{1}$, Luis Roberto Manzione Nadal ${ }^{1}$, Gabriel Maccapani ${ }^{1}$, Marília Fernandes ${ }^{1}$ and Franco \\ Milan Sapuppo ${ }^{2}$ \\ ${ }^{1}$ General, Gastric and Minimally Invasive Surgery - Albert Einstein Jewish Hospital \\ ${ }^{2}$ General Surgery Resident, Heliópolis Hospital, São Paulo, SP, Brazil
}

Corresponding author: Marina Gabrielle Epstein, General, Gastric and Minimally Invasive Surgery - Albert Einstein Jewish Hospital, Brazil.

Received date: June 12, 2021; Accepted date: August 10, 2021; Published date: September 04, 2021

Citation: Marina Gabrielle Epstein, Vladimir Schraibman, Luis Roberto Manzione Nadal, Gabriel Maccapani, Marília Fernandes and Franco Milan Sapuppo (2021) Conservative Treatment of Idiopathic Spontaneus Pneumoperitoneum. J, Surgical Case Reports and Images 4(7); DOI: $10.31579 / 2690-1897 / 085$

Copyright: (C) 2021, Marina Gabrielle Epstein, This is an open access article distributed under the Creative Commons Attribution License, which permits unrestricted use, distribution, and reproduction in any medium, provided the original work is properly cited.

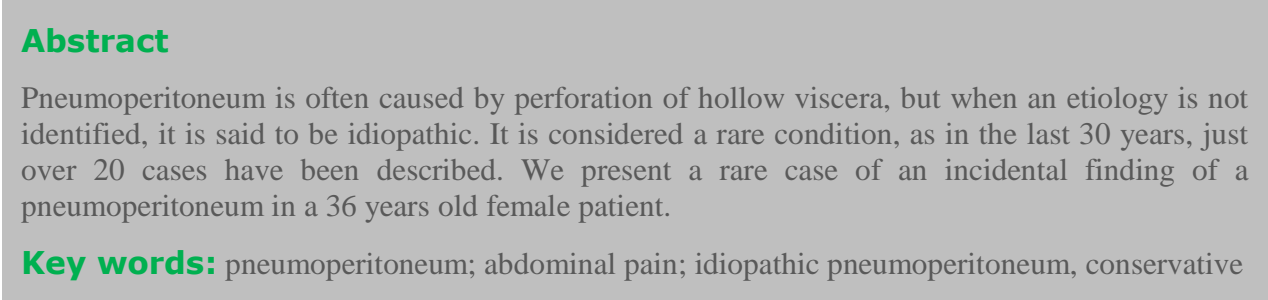

\section{Introduction}

Idiopathic spontaneous pneumoperitoneum (ISP) is an unusual condition, which is characterized by the presence of gas in the intraperitoneal space without gastrointestinal perforation. There is no clear etiology for it [1, 2].

This study reports an unusual presentation of an idiopathic pneumoperitoneum which has put the surgeon in a massive diagnostic and therapeutic challenge with a 36 year old patient with spontaneous idiopathic pneumoperitoneum. In this case, the patient was admitted for strict clinical observation and chosen for non-surgical treatment.

\section{Case Report}

A 36-year-old female patient searched emergency care due to chest and shoulder pain associated with mild abdominal discomfort. She denied vomiting, altered bowel habits, eating food with a possible foreign body (toothpick/bones). Personal history reported a laparoscopic Nissen fundoplication 9 months ago due to gastroesophageal reflux only.

The patient reported having sexual intercourse 96 hours before the onset of symptoms. On examination, she was in good general condition, hemodynamically stable, with no changes in cardiac and pulmonary auscultation, flabby abdomen, little pain on diffuse palpation, sudden negative decompression negative.

The hospital's chest pain protocol was opened. ECG and cardiac enzymes unchanged. Chest X-rays showed pneumoperitoneum (Figure 1).

In view of the findings, chest and total abdomen $\mathrm{CT}$ without contrast were requested which showed: topical fundoplication, mild pneumomediastinum, pneumoperitoneum, more evident in the upper abdomen, and in perigastric / periduodenal planes without free fluid (figure 2). 


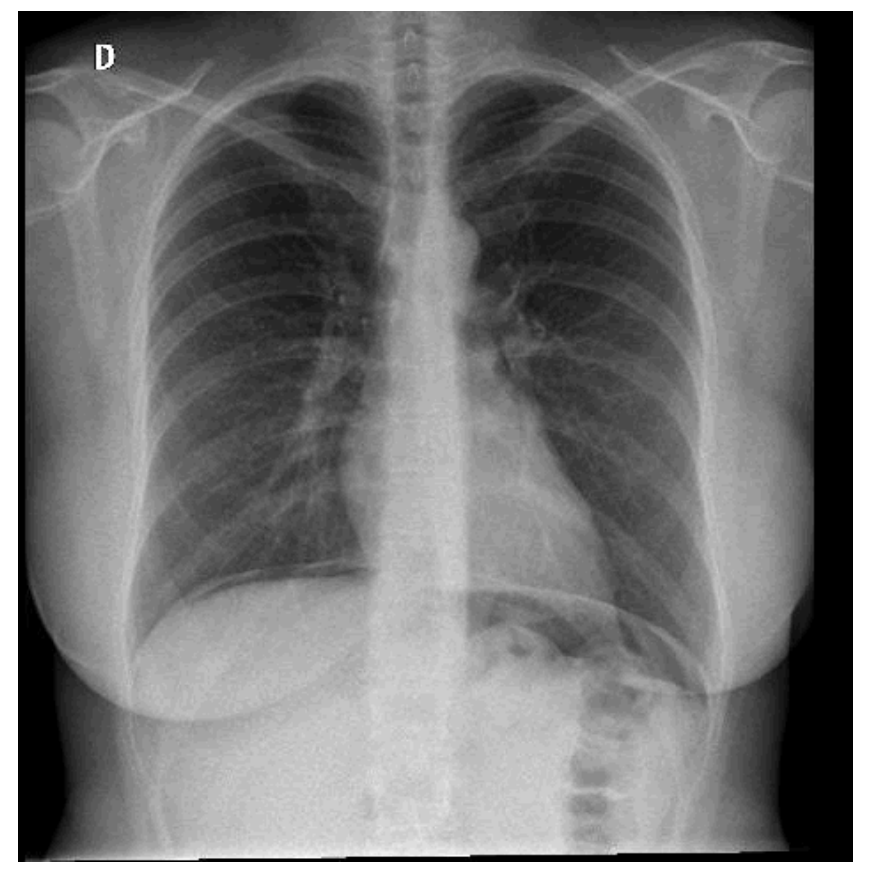

Figure 1: Chest X-rays - pneumoperitoneum

There were no signs of gynecological disease or gastrointestinal tract perforation

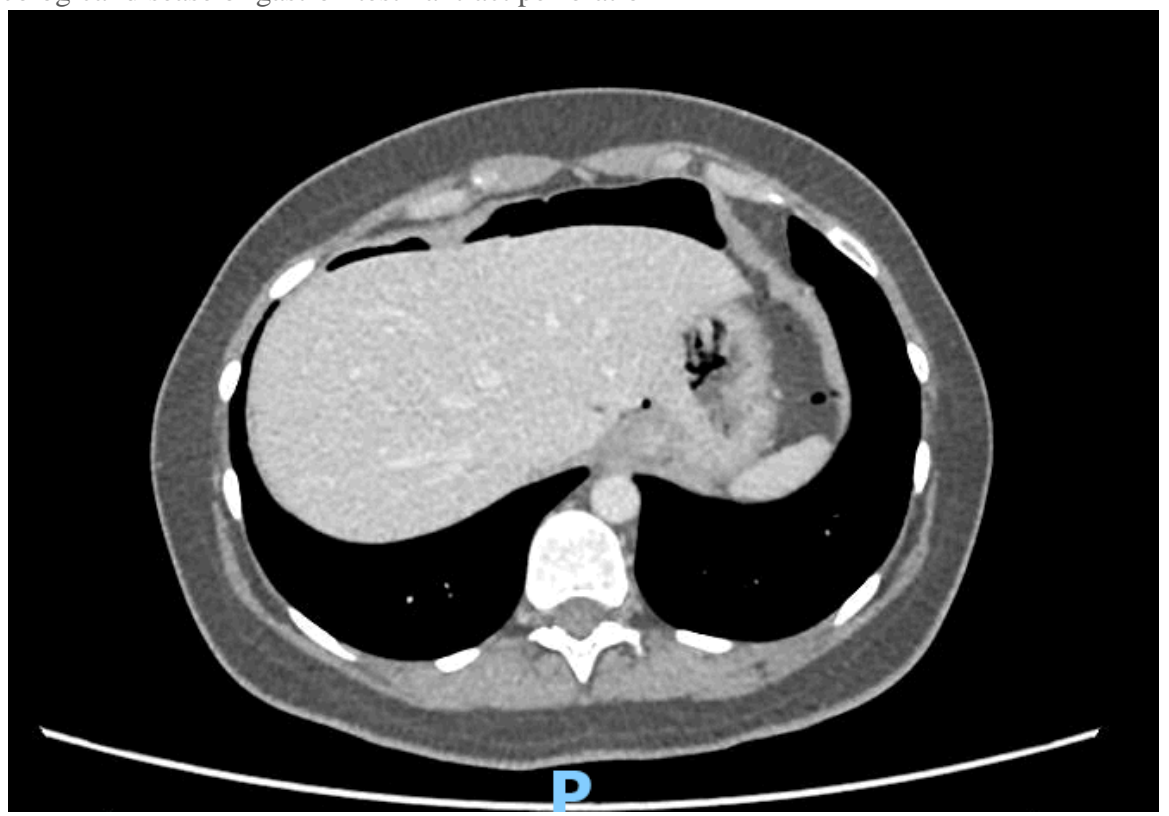

Figure 2: Abdominal CT confirmed pneumoperitoneum

In view of the findings, the patient was asked to complete the exam with oral contrast and was later submitted to a new tomography and there was no contrast extravasation. Laboratory tests such as blood count, Creactive protein, kidney and liver function showed no changes.

Based on these findings, we diagnosed the patient with ISP. She was treated conservatively with close observation and serial abdominal examination. She was admitted with intravenous antibiotic therapy, absolute fasting and parenteral diet.

Next day, the patient no longer had abdominal discomfort and shoulder pain. $\mathrm{CBC}$ and PCR remained unchanged. A new control tomography was performed after 48 hours and a decrease in pneumoperitoneum was noticed. Upper gastrointestinal endoscopy was performed 96 hours after admission without signs of micro perforation or changes in fundoplication.

The patient was given a liquid diet and accepted it without complications. She was discharged asymptomatic from the hospital after 7 days under follow-up.

\section{Discussion}

Pneumoperitoneum, in general, originates from surgical and non-surgical causes, mostly due to perforated gastric or duodenal ulcer, but in $10 \%$ of 
cases, it may be of idiopathic etiology, characterized by a rare condition, with an average than twenty reports in the literature [1, 2, 3].

Intra-thoracic causes include thoracic trauma, post-cardio-pulmonary resuscitation and excessive mechanical ventilation with high peak inspiratory pressures $[3,4]$. In these cases, pneumoperitoneum is usually a result of raised intra-thoracic pressure, which leads to the leakage of intrathoracic air through microscopic pleural and diaphragmatic defects, and pneumomediastinum often co-exists. In such cases, management of pneumoperitoneum is typically conservative. In the female population, gynaecological causes such as sexual intercourse, vaginal douching, vaginal insufflation, and pelvic inflammatory disease, should be considered and are usually a result of anatomical communication between the peritoneal cavity and the fallopian tubes and endometrium [4].

Finally, there exists a group of patients with pneumoperitoneum who have no clear etiology or risk factors; these are true cases of idiopathic pneumoperitoneum. Our patient is an exceedingly rare case of idiopathic pneumoperitoneum who had very few abdominal symptoms and a completely innocent physical examination.

It is imperative to carry out an adequate anamnesis in order to distinguish between surgical and non-surgical conditions, in relation to the pneumoperitoneum [5].

There is the question of the presence or not of peritonitis in the clinical examination, which plays a central role in the management of the case. The computed tomography exam may point out the underlying causes for the pathology. This exam has an accuracy of $86 \%$ in relation to the identification of perforations [5]. The absence of peritonitis allows the possibility of continuing with conservative treatment, maintaining strict observation of patient. There is documentation in the medical literature of successful conservative treatment, with measures such as intravenous antibiotics, fasting, total parenteral nutrition, biochemical follow-up exams and serial imaging exams [5].

\section{Conclusion:}

ISP it a benign condition, but is not a simple diagnosis and should be considered as one of exclusion after discarding surgical causes. It is important to have a notion of the occurrence of cases like this so that the diagnosis can be made with certainty. Imaging exams help to avoid unnecessary laparotomies.

\section{References}

1. Karaman A, Demirbilek S, Akin M, Gürünlüoğlu K, Irşi C. (2005) Does pneumoperitoneum always require laparotomy? Report of six cases and review of the literature. Pediatr Surg Int. 21:819-824

2. Alassaf M. (2015) Recurring spontaneous aseptic pneumoperitoneum presenting secondary to an unrelated chief complaint: A case report. Int J Surg Case Rep. 7C:96-98. doi:10.1016/j.ijscr.2014.10.038

3. Amaral RN, Valadares LC, Antunes RV, Matos BP, Alquimim AF, Mazon G. (2017) Pneumoperitônio idiopático em idoso. J Health Biol Sci. 5(3):286-288.

4. P. Sooby, R. Harshen, R. Joarder (2015) An unusual triad of pneumatosis intestinalis,portal venous gas and pneumoperitoneum in an asymptomatic patient. J. Surg. Case Rep. 2015 (4):rjv035. doi: 10.1093/jscr/rjv035.

5. Sidiqi MM, Fletcher D, Billah T. (2020) The enigma of asymptomatic idiopathic pneumoperitoneum: A dangerous trap for general surgeons. Int $J$ Surg Case Rep. 76:33-36. doi:10.1016/j.ijscr.2020.09.149

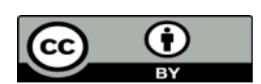

This work is licensed under Creative Commons Attribution 4.0 License

To Submit Your Article Click Here: Submit Manuscript

DOI: $10.31579 / 2690-1897 / 085$
Ready to submit your research? Choose Auctores and benefit from:

*ast, convenient online submission
*igorous peer review by experienced research in your field
*apid publication on acceptance
* authors retain copyrights
* imique DOI for all articles
immediate, unrestricted online access

At Auctores, research is always in progress.

Learn more auctoresonline.org/journals/journal-of-surgical-case-reportsand-images 